Tropical Journal of Pharmaceutical Research April 2017; 16 (4): 861-866

ISSN: $1596-5996$ (print); 1596-9827 (electronic)

(C) Pharmacotherapy Group, Faculty of Pharmacy, University of Benin, Benin City, 300001 Nigeria.

All rights reserved.

Available online at http://www.tjpr.org

Original Research Article

http://dx.doi.org/10.4314/tjpr.v16i4.16

\title{
Protective effect of alcohol extract of Yulangsan leaf on chemically-induced liver injury in mice
}

\author{
Yiping Feng ${ }^{1}$, Yang $\mathrm{Jiao}^{2}$ and Renbin Huang ${ }^{2 *}$ \\ ${ }^{1}$ School of Medicine, Guangxi University of Science and Technology, Liuzhou, Guangxi 545005, ${ }^{2}$ Department of Pharmacology, \\ Guangxi Medical University, Nanning 530021, China \\ *For correspondence: Email: sfc854@163.com
}

\begin{abstract}
Purpose: To investigate the protective effect of Millettia pulchra Kurz var. Laxior (Dunn) Z. Wei (Yulangsan) leaf (YLSL) on chemically-induced liver injury in mice.

Methods: Models of carbon tetrachloride $\left(\mathrm{CCl}_{4}\right)$ and D-galactosamine (D-GalN)-induced liver injury in Kunming mice were prepared by intraperitoneal injection. Sixty mice were randomly divided into normal saline (NS) group, liver-injury group, low-, medium- and high-dose YLSL groups (7.5, 15 and $30 \mathrm{~g} / \mathrm{kg}$ dose, respectively), and biphenyldicarboxylate (BPDC) group, with 10 animals per group. Indices for liver, spleen and thymus were assessed. Serum aspartate transaminase (AST) and alanine aminotransferase (ALT) activities, levels of malondialdehyde (MDA) in liver tissues and reduced glutathione (GSH) as well as activities of superoxide dismutase (SOD) and glutathione peroxidase (GSH-PX) in liver tissue were assayed. Liver tissue damage was assessed histologically.

Results: YLSL could significantly decrease the elevation of AST or ALT in liver injuries induced by $\mathrm{CCl}_{4}$ or D-GalN in mice, which showed a dose-effect relationship obviously. The high dose YLSL significantly decreased thymus weight relative to $C \mathrm{Cl}_{4}$ and D-GalN (CCL $\mathrm{CCL}_{4}+\mathrm{YLSL}: 4.4213 \pm 1.0544 \mathrm{vs} 3.7120 \pm$ 0.8534; D-GalN vs YLSL + D-GalN: $3.7272 \pm 1.1655$ vs $1.9548 \pm 1.2996, p<0.01)$. However, SOD activity was significantly increased $(p<0.01, p<0.05)$. In treatment groups exposed to CCl4, GSH-PX activity was significantly increased $(p<0.01)$ and GSH levels decreased (middle dose group and positive control group). In treatment groups with D-GalN, GSH content was significantly increased ( $p<$ 0.01 or $p<0.05)$, while GSH-Px activity decreased $(p<0.01)$.

Conclusion: YLSL has protective effect against chemically-induced liver injury in mice. The mechanism may be related to attenuation of free radical-induced lipid peroxidation.
\end{abstract}

Keywords: Millettia pulchra, Liver injury, Biochemical parameters, Thymus, Antioxidant, Dgalactosamine, Biphenyldicarboxylate

Tropical Journal of Pharmaceutical Research is indexed by Science Citation Index (SciSearch), Scopus, International Pharmaceutical Abstract, Chemical Abstracts, Embase, Index Copernicus, EBSCO, African Index Medicus, JournalSeek, Journal Citation Reports/Science Edition, Directory of Open Access Journals (DOAJ), African Journal Online, Bioline International, Open-J-Gate and Pharmacy Abstracts

\section{INTRODUCTION}

Millettia pulchra Kurz var. Laxior(Dunn)Z. Wei also known as Yulangsan (YLS) or Longyanshen, is used as an analgesic, antiinflammatory, sedative memory-enhancing, immunity-boosting and anti-stress agent. The roots of YLS contain flavonoids [2], saponins [3] and polysaccharides [4]. Studies have shown that the aqueous extract of YLS roots has hypotensive, free radical-scavenging, myocardial ischemia and reperfusion injury-reducing properties [5]. It also has anti-dementia and antiinflammatory [6], as well as hepatoprotective effects $[7,8]$. Studies have so far concentrated mostly on Yulangsan roots, to the exclusion of the leaves. 
In the present study, the hepatoprotective effects of alcohol extract of Yulangsan leaves against chemical-induced liver injury were investigated in SPF Kunming mice through a combination of biochemical and histological procedures.

\section{EXPERIMENTAL}

\section{Animals}

SPF Kunming mice (half male and half female, weighing $20 \pm 2 \mathrm{~g}$ ) were provided by the Guangxi Medical University Experimental Animal Center (Shuangyong Road No. 22, Nanning City, Guangxi Province, China). Experimental animal production and occupation licenses were SCXKG Gui 2009-0002, and SYXKG Gui 2009-0004, respectively. This research was approved by the Animal Ethical Committee of Guangxi Medical University Experimental Animal Center according to "Principles of Laboratory Animal Care" (NIH publication no. 85-23, revised 1985) [7].

\section{Materials and reagents}

The plant was collected from Xinxu in the suburb of Lingshan Guangxi Province in 2014, and was identified as Millettia pulchra Kurz var. Laxior (Dunn) Z.Wei (Yulangsan) leaf by Professor Maoxiang Nai (Guangxi institute of Chinese Medicine \& Pharmaceutical Science, Nanning). A voucher specimen (no. YLS 201406-03) was kept at the herbarium of Experimental Center Of The School Of Pharmacy, Guangxi Medical University. Yulangsan leaf (YLSL) alcohol extract was prepared by a method utilizing $70 \%$ methanol for extraction for $2 \mathrm{~h}$ at reflux; analytical grade carbon tetrachloride $\left(\mathrm{CCl}_{4}\right)$ was purchased from Chengdu Kelong Chemical Reagent Factory (Sichuan, China). D-GalN was provided by MP Biomedicals LLC (Shanghai, China). Bifendate dropping pills were purchased form Guangzhou Xingqun Pharmaceutical Co., Ltd (Guangdong Province, China); sodium chloride injection were purchased from Guizhou Tiandi Pharmaceutical Co., Ltd. (Guangdong Province,China), while Coomassie blue detection kit was obtained from Nanjing Jiancheng Bioengineering Institute (Nanjing City, China). Other reagents were of analytical grade.

\section{Instruments and equipment}

Visible spectrophotometer was product of Shanghai Precision Scientific Instrument Co., Ltd, Model 722S; electronic balance: ZA1003 (Sartorius (Shanghai) Trading Company Ltd); low-speed large-capacity desktop centrifuge was obtained from Shanghai Anting Scientific Instrument Factory (Shanghai, China); model
TDL-5, trace desktop centrifuge model CL17R, was product of Thermo Company (Shanghai, China); high-speed refrigerated centrifuge was from Shanghai Anting Scientific Instrument Factory (Shanghai, China); model TGL-16G-A and vortex mixer were products of Shanghai Medical Instrument Factory (Shanghai, China). Water ultra-purification System (Model UPT-II20T) was supplied by Chengdu Chaochun Technology Co., Ltd (Sichuan Province, China); stainless steel electric heated-water bath, model GSY-ii was from Beijing Medical Equipment factory (Beijing, China); while color pathological image analysis system PTPS-2011 was supplied by Chongqing Tianhai Medical Equipment Co., Ltd (Chongqing, China).

\section{Animal models}

Healthy Kunming mice of both sexes (mean weight $=20 \pm 2 \mathrm{~g}$ ) were randomly assigned to six groups, with each group having 5 male and 5 female mice. The groups were normal control group, $\mathrm{CCl}_{4}$ model group, biphenyldicarboxylate (BPDC, (150 mg/kg body weight) positive control group, and three groups given different doses (high, medium and low) of alcohol leaf extract of Yulangsan, i.e., YLSLH, YLSLM, YLSLL groups which received 30,15 and $7.5 \mathrm{~g}$ YLSL/kg body weight, respectively. Mice in positive control group received intraperitoneally (i.p.) $0.02 \mathrm{~mL}$ $\mathrm{ml} / \mathrm{g}$; the $\mathrm{CCl}_{4}$ model group received the same dose of NS i.p. while mice in the treatment groups received their respective doses of YLSL i.p., in addition to NS. All treatments were given once daily for 7 days, and $1 \mathrm{~h}$ after the last administration, all the groups were injected with $0.1 \% \mathrm{CCl}_{4}$ in peanut oil [10] at a dose of 0.1 $\mathrm{mL} / 10 \mathrm{~g}$, except the normal control group which got peanut oil injection in place of $0.1 \% \mathrm{CCl}_{4}(0.1$ $\mathrm{mL} / 10 \mathrm{~g}$ ). The mice fasted for $16 \mathrm{~h}$ but had free access to drinking water, and the D-GalN model group was given (i.p.) D-GalN solution (800 $\mathrm{mg} / \mathrm{kg}$ ) with the capacity of $0.2 \mathrm{~mL} / 10 \mathrm{~g}$ [11], and fasted for $16 \mathrm{~h}$ with access to drinking water [12].

\section{Determination of serum biochemical indicators}

Blood was taken from the retro-orbital plexus, allowed to coagulate, and centrifuged at 3000 $\mathrm{rpm}$ at $0{ }^{\circ} \mathrm{C}$ for $10 \mathrm{~min}$. The serum was stored at $-5^{\circ} \mathrm{C}$, and used for assay of serum AST and ALT with kits according to manufacturer's instructions.

\section{Calculation of visceral indices of liver, spleen and thymus}

The mice were sacrificed by decapitation; the fat and mesentery were quickly cut off on an ice tray 
in an ice-water bath of physiological saline. The liver, spleen and thymus were excised and rinsed with ice-cold physiological saline to remove accumulated blood. The organs were blotted and weighed; and visceral indices were calculated as follows: liver index = liver weight $(\mathrm{g})$ divided by body weight $(\mathrm{g})$, thymus index = thymus weight (mg) divided by body weight $(\mathrm{g}$ ) and spleen index $=$ spleen weight $(\mathrm{mg})$ divided by body weight $(\mathrm{g})$.

\section{Preparation of liver homogenates and examination}

The right lobe of the liver was selected and rinsed with cold saline to remove blood clots, then weighted after blotting. Ten percent (10\%) liver homogenate was prepared in $0.9 \%$ sodium chloride solution. The homogenate was centrifuged at $3500 \mathrm{rpm}$ at $4{ }^{\circ} \mathrm{C}$ for $15 \mathrm{~min}$, and the supernatant was refrigerated at $-5^{\circ} \mathrm{C}$ prior to use.

Biochemical indices in liver homogenate were assayed with kits were MDA (with thiobarbituric acid); SOD (xanthine oxidase method); GSH and GSH-PX, while protein content was determined by the Coomassie brilliant blue method [13].

\section{Histological examination of liver tissue}

Small sections of liver tissue were taken $0.5 \mathrm{~cm}$ from the edge of liver leaf edge, and fixed in 10 $\%$ formalin fixative at $4{ }^{\circ} \mathrm{C}$ overnight. The tissue was sectioned (cut into about $2 \mathrm{~mm}$ thickness) and $\mathrm{HE}$ stained, then the morphological changes in liver tissue were observed under light microscope.

\section{Statistics}

SPSS 18.0 software was applied for statistical analysis. The data are presented as mean \pm standard deviation (SD). The means of multigroups were compared using analysis of variance. $P<0.05$ or 0.01 was taken as statistically significant.

\section{RESULTS}

\section{Effect of YLSL on visceral index of mice}

For mice with $\mathrm{CCl}_{4}$-induced acute liver injury, both YLSLH and YLSLM significantly reduced thymus index $(p<0.01)$. YLSLH reduced spleen index $(p<0.01)$. However, the different doses of YLSL had no significant effect on liver index.

For mice with D-GalN-induced acute liver injury, the three doses of YLSL had no significant effect on liver index and spleen index. However YLSLH significantly lowered thymus index $(p<0.05$; Table 1).

\section{Effect of YLSL on serum biochemical parameters}

Experimental results demonstrated that for mice with $\mathrm{CCl}_{4}$-induced acute liver injury, YLS leaf alcohol extract at low dose significantly reduced the activity of serum AST $(p<0.01)$, while the middle dose significantly reduced the activity of serum ALT $(p<0.05)$. High dose of the extract resulted in significant reduction of MDA $(p<0.05)$, while each of the three doses significantly enhanced the activities of SOD and GSH-PX $(p<0.01)$.

For mice with D-GalN-induced acute liver injury, low dose of YLS leaf alcohol extract reduced the activity of serum AST $(p<0.01)$; each dose significantly decreased serum ALT activity (low- and middle-dose: $p<0.01$, high dose: $p<$ 0.05).

Middle- and high-doses resulted in significantly decreased content of MDA ( $p<0.01$ or $<0.05)$, while each of the three dose significantly increased GSH content (high- and middle-

Table 1: Effect of YLSL on liver, spleen and thymus indices in $\mathrm{CCl}_{4}$ or D-GalN-induced acute liver injury in mice

\begin{tabular}{|c|c|c|c|}
\hline Group & $\begin{array}{l}\text { Liver index } \\
(\%) \\
\end{array}$ & $\begin{array}{l}\text { Spleen index } \\
(\mathrm{mg} / \mathrm{g})\end{array}$ & $\begin{array}{c}\text { Thymus index } \\
(\mathrm{mg} / \mathrm{g})\end{array}$ \\
\hline $\mathrm{NC}$ & $0.0460 \pm 0.0037$ & $4.0807 \pm 0.7729$ & $3.7120 \pm 0.8534$ \\
\hline $\mathrm{CCl}_{4}$ model & $0.0472 \pm 0.0033$ & $3.8743 \pm 0.9183$ & $4.4213 \pm 1.0544$ \\
\hline $\mathrm{BPDC}+\mathrm{CCl}_{4}$ & $0.0506 \pm 0.0047$ & $4.3336 \pm 0.5902$ & $3.8805 \pm 1.2399$ \\
\hline $\mathrm{YLSLL} \mathrm{CCl}_{4}$ & $0.0479 \pm 0.0033$ & $4.3535 \pm 0.9405$ & $3.8722 \pm 1.8661$ \\
\hline $\mathrm{YLSLM} \mathrm{CCl}_{4}$ & $0.0496 \pm 0.0035$ & $3.4046 \pm 0.6768$ & $2.8778 \pm 0.5853^{\star *}$ \\
\hline $\mathrm{YLSLH}+\mathrm{CCl}_{4}$ & $0.0498 \pm 0.0037$ & $3.2068 \pm 0.3859 *$ & $2.7682 \pm 0.7235^{\star \star}$ \\
\hline NC & $0.0474 \pm 0.0097$ & $4.1739 \pm 0.7232$ & $3.7654 \pm 1.0897$ \\
\hline D-GalN model & $0.0543 \pm 0.0049$ & $4.1427 \pm 1.4056$ & $3.7272 \pm 1.1655$ \\
\hline BPDC+D-GalN & $0.0631 \pm 0.0061^{* *}$ & $4.5190 \pm 0.9977$ & $3.9386 \pm 0.8912$ \\
\hline YLSLL+D-GalN & $0.0567 \pm 0.0113$ & $4.5056 \pm 0.7446$ & $3.3667 \pm 1.4537$ \\
\hline YLSLM+D-GalN & $0.0563 \pm 0.0081$ & $3.7721 \pm 1.2645$ & $3.1694 \pm 0.8226$ \\
\hline YLSLH+D-GalN & $0.0571 \pm 0.0073$ & $3.0471 \pm 0.9327$ & $1.9548 \pm 1.2996 *$ \\
\hline
\end{tabular}


dose: $p<0.01$, low dose: $p<0.05$ ). However, each dose significantly increased SOD activity $(p<0.01)$ (Table 2).

\section{Effect of YLSL on liver histopathology $\mathrm{CCl}_{4^{-}}$ and D-GalN-induced acute liver injury}

Under the microscope, clear clobular contours, prominent nucleoli, abundant and uniform cytoplasm of hepatocytes, and visible liver sinusoidal cord could be seen in normal mice. After acute liver injury, hepatic lobules were unclear, the cytoplasm was bright and empty with sparse, lightly stained, irregular particles, and the liver cells became enlarged. Besides ballooning degeneration, nuclear condensation and focal necrosis were evident. However, each dose of YLSL relieved the liver cell swelling, as well as focal and zonal necrosis. The results are as shown in Figure 1.

\section{DISCUSSION}

There are varieties of enzymes which reflect liver cell injury and the extent of damage. These include ALT, AST, GGT, GLD, and SOD. ALT is the most sensitive indicator of liver cell injury [14]. In general, increased activity of serum ALT is positively correlated with degree of hepatocellular disease. Increased serum AST and ALT activities are of significance in the diagnosis of hepatitis, although ALT is a more reliable index than ALT. The activities of ALT and ASTin the $\mathrm{CCl}_{4}$ and D-GalN models were significantly elevated, with variation in ALT greater than that in AST, suggesting that liver tissue damage was successfully induced in these models.

MDA is the end product of lipid peroxidation, which indirectly reflects the severity of free radical attack on cells [15]. SOD is an important antioxidant enzyme system which indirectly reflects ability to scavenge oxygen free radicals $[16,17]$. Therefore, MDA levels are often correlated with SOD. In this study, SOD activities in the $\mathrm{CCl}_{4}$ and $\mathrm{D}$-GalN models were significantly lower than SOD activities in the treatment groups $(p<0.01)$. This indicates that alcohol leaf extract of Yulangsan has hepatoprotective effects, most probably through inhibition of lipid peroxidation. GSH, a tripeptide composed of glutamic acid, cysteine and glycine, is an important non-protein thiol compound which belongs to low-molecular scavengers. GSH can eliminate $\mathrm{O}_{2}^{-}, \mathrm{H}_{2} \mathrm{O}_{2}$ and $\mathrm{LOOH}$, and is necessary for the decomposition of hydrogen peroxide. Besides, GSH can stabilize thiol-containing enzymes and prevent hemoglobin and other cofactors from oxidative damage. Deficiency of GSH or its depletion will lead to toxic effects or aggravated toxic effects by many chemicals or environmental factors. Thus, GSH is an index of antioxidant capacity.

The determination of activities of GSH and GSH$P x$ are useful for understanding the mechanism of drug action. In the treatment groups exposed to $\mathrm{CCl}_{4}, \mathrm{GSH}-\mathrm{Px}$ activity was significantly increased $(p<0.01)$ and GSH levels decreased (middle dose group and positive control group). In the treatment groups with D-GalN, GSH content was significantly increased $(p<0.01$ or $p$ $<0.05$ ), while GSH-Px activity decreased ( $p<$ $0.01)$.

Thus, an inverse relationship was observed between GSH and GSH-Px, i.e., when GSH reduced, GSH-Px increased, and vice versa. This suggests that the alcohol extract of Yulangsan on the one hand promoted the synthesis of $\mathrm{GSH}$, while on the other hand, it accelerates the conversion of GSH to GSSG.

Table 2: Effect of YLSL on serum and hepatic parameters in $\mathrm{CCl}_{4}$ - and $\mathrm{D}$-GalN-induced acute liver injured mice

\begin{tabular}{|c|c|c|c|c|c|c|}
\hline Group & AST & ALT & $\begin{array}{c}\text { MDA } \\
\text { nmol/mgprot }\end{array}$ & $\begin{array}{c}\text { GSH } \\
(\mathrm{gGSH} /)\end{array}$ & $\begin{array}{c}\text { SOD } \\
\text { (U/mgprot) }\end{array}$ & GSH-PX \\
\hline & $72.72 \pm 23.69^{* *}$ & $24.35 \pm 9.05^{\star *}$ & $2.46 \pm 0.43^{\star *}$ & $0.73 \pm 0.19^{\star}$ & $160.31 \pm 20.25^{\star *}$ & $133.28 \pm 47.15$ \\
\hline $\mathrm{CCl}_{4}$ model & $107.13 \pm 21.70$ & & $.04 \pm 1.10$ & $0.94 \pm 0.36$ & $123.33 \pm 28.33$ & \\
\hline $\mathrm{BPDC}+\mathrm{CCl}_{4}$ & $77.19 \pm 17.18^{\star *}$ & $22.25 \pm 10.88^{\star *}$ & $3.08 \pm 0.65^{\star}$ & $0.65 \pm 0.13^{\star}$ & $187.74 \pm 42.33^{* *}$ & 362.60 \\
\hline $\mathrm{YLSL}_{\mathrm{L}}+\mathrm{CCl}_{4}$ & $80.50 \pm 9.57^{* *}$ & $66.58 \pm 27.98^{*}$ & $4.42 \pm 0.98$ & $0.82 \pm 0.11$ & $209.55 \pm 25.10^{* *}$ & 412 \\
\hline & & & $.55 \pm 0.66$ & $.65 \pm 0.11^{*}$ & $175.66 \pm 32.95^{\star *}$ & \\
\hline $\mathrm{YLSL}_{\mathrm{H}}+\mathrm{CCl}_{4}$ & & & $98 \pm 0.81^{*}$ & $1.02 \pm 0.18$ & $165.36 \pm 35.34^{* *}$ & \\
\hline & & & & $.77 \pm 0.98$ & $169.79 \pm 64.97$ & \\
\hline & & & & $18 \pm 0.55$ & $142.57 \pm 22.40$ & \\
\hline & & & $7.08 \pm 2.69^{* *}$ & $4.72 \pm 5.22^{*}$ & $195.64 \pm 43.92^{* *}$ & $323.74 \pm 49.54^{* *}$ \\
\hline & $118.83 \pm 93.71^{\text {** }}$ & $103.74 \pm 86.34^{\star *}$ & $10.89 \pm 5.58$ & $4.01 \pm 4.05^{\star}$ & $210.74 \pm 35.55^{\star *}$ & $365.62 \pm 65.52^{*}$ \\
\hline $\mathrm{YLSL}_{M}+\mathrm{D}-\mathrm{GaIN}$ & $163.70 \pm 155.36$ & $135.22 \pm 97.96^{\star *}$ & $8.08 \pm 3.53^{\star}$ & $2.38 \pm 0.93^{\star *}$ & $190.60 \pm 27.55^{\text {** }}$ & $289.77 \pm 76.09^{\star *}$ \\
\hline $\mathrm{YLSL}_{H}+\mathrm{D}-\mathrm{GalN}$ & $210.67 \pm 109.91$ & $138.19 \pm 138.57^{*}$ & $6.37 \pm 2.07^{* *}$ & $4.19 \pm 3.06^{\star *}$ & $198.90 \pm 30.12^{* *}$ & $333.56 \pm 68.27^{\star *}$ \\
\hline
\end{tabular}

Values expressed are as mean $\pm \mathrm{SD}(\mathrm{n}=10) ;{ }^{\star} p<0.05,{ }^{\star *} p<0.01 \mathrm{vs} \mathrm{CCl}_{4}$ control and D-GalN control groups 


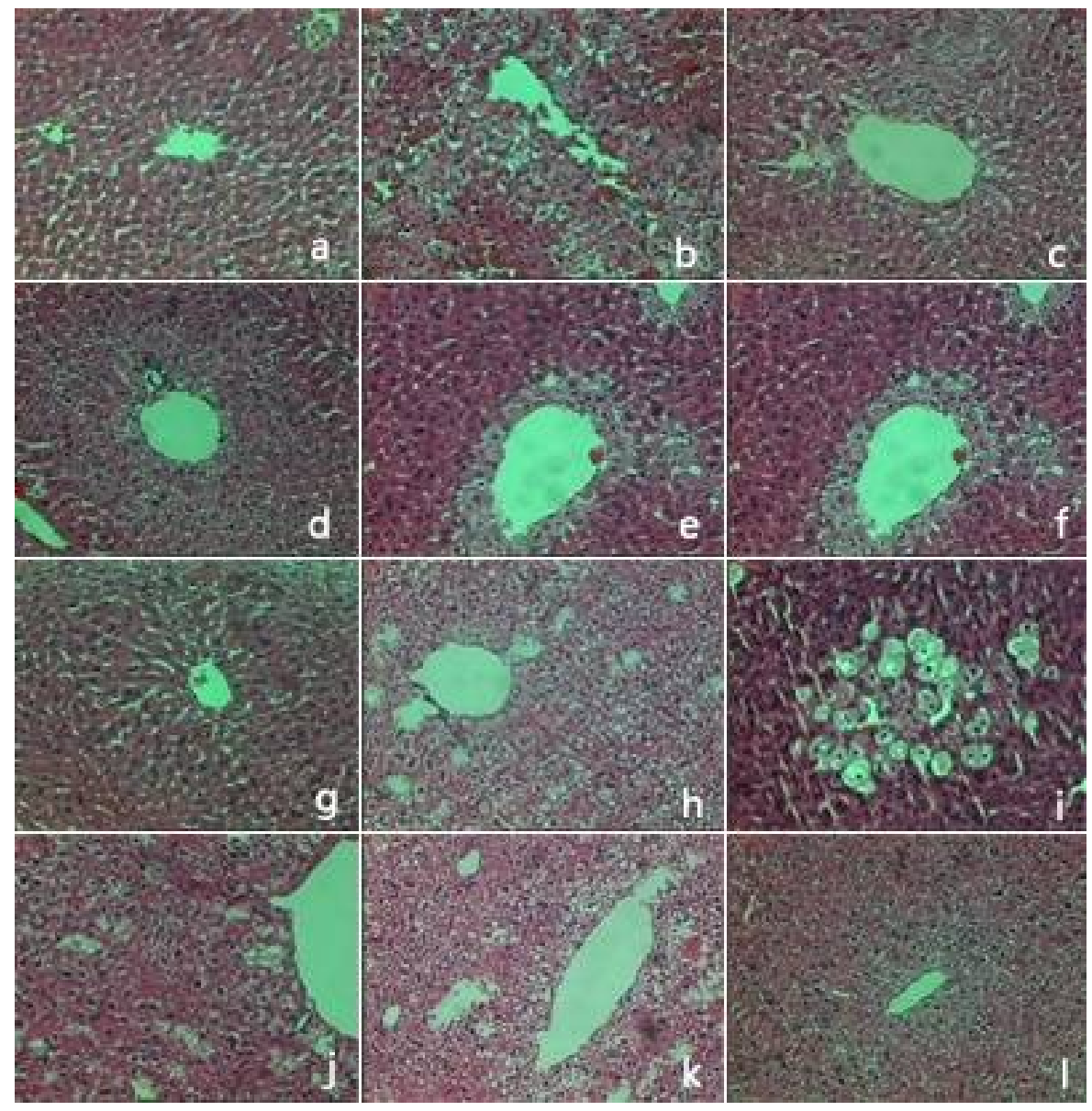

Figure 1: Photomicrograph of liver tissue (H\&E $\times 100)$. a: oil alone-treated mice; $b: \mathrm{CCl}_{4}$ alonetreated mice ; $c$ : mice pretreated with YLSL $(30 \mathrm{~g} \bullet \mathrm{kg}-1 \cdot \mathrm{d}-1 \times 7 \mathrm{~d})$ before treatment with $\mathrm{CCl}_{4}$; $d$ : mice pretreated with YLSL $(15 \mathrm{~g} \cdot \mathrm{kg}-1 \cdot \mathrm{d}-1 \times 7 \mathrm{~d})$ before treatment with $\mathrm{CCl}_{4} ; \mathrm{e}$ : pretreated with YLSL $(7.5 \mathrm{~g} \cdot \mathrm{kg}-1 \cdot \mathrm{d}-1 \times 7 \mathrm{~d})$ before treatment with $\mathrm{CCl}_{4}$; $\mathrm{f}$ : mice pretreated with $B P D C(150 \mathrm{mg} \cdot \mathrm{kg}-1 \cdot \mathrm{d}-$ $1 \times 7 d)$ before treatment with $\mathrm{CCl}_{4} ; \mathrm{g}$ : NC alone-treated mice; $h$ : $D$-GalN alone-treated mice; i: mice pretreated with YLSL $(30 \mathrm{~g} \cdot \mathrm{kg}-1 \cdot \mathrm{d}-1 \times 7 \mathrm{~d})$ before treatment with $D-G a I N ; j$ : mice pretreated with $Y L S L(15 \mathrm{~g} \cdot \mathrm{kg}-1 \cdot \mathrm{d}-1 \times 7 \mathrm{~d})$ before treatment with $D$-GalN; $\mathrm{k}$ : mice pretreated with YLSL $(7.5 \mathrm{~g} \cdot \mathrm{kg}$ $1 \cdot d-1 \times 7 d)$ before treatment with $D$-GalN; I: mice pretreated with BPDC $(150 \mathrm{mg} \cdot \mathrm{kg}-1 \cdot d-1 \times 7 d)$ before treatment with $D$-GalN

Histological examination is a visual indicator of organ or tissue damage. In this study, $\mathrm{CCl}_{4}$ induced liver damage was reflected in cellular necrosis, hemorrhage in the central vein and fatty degeneration. In the D-GalN model group, features seen in histology included diffuse multiple patchy necrosis, cells with a large number of toxic granule with positive PAS staining and more eosinophilic corpuscles. These features are similar to the damage caused by viral hepatitis. The different doses of Yulangsan leaf alcohol extract exhibited varying degrees of relief on the $\mathrm{CCl}_{4}$ and D-GalN-induced liver cell swelling, necrosis, fatty degeneration, inflammatory cell infiltration and other pathological changes. This shows that the extract has a protective effect against acute liver injury, through a mechanism involving neutralizing oxygen free radicals and inhibiting lipid peroxidation.

\section{CONCLUSION}

YLSL lowers the elevated activities of ALT, AST in acute liver injury mice-induced by $\mathrm{CCl}_{4}$ and $\mathrm{D}$ GalN, ameliorates liver pathological condition and have protective effects against CC14induced acute liver injury. The protective effects of wedelolactone against $\mathrm{CCl}_{4}$ and D-GalNinduced acute liver injury are related to its ability to attenuate oxygen free radicals and inhibit lipid peroxidation. The results of this study provide a further understanding of the pharmacological effects of YLSL as well as the need for further studies of the plant. 


\section{DECLARATIONS}

\section{Acknowledgement}

This work was financially supported by Guangxi Education Department Science Research Foundation (no. KY2015LX191).

\section{Conflict of Interest}

No conflict of interest associated with this work.

\section{Contribution of Authors}

The authors declare that this work was done by the authors named in this article and all liabilities pertaining to claims relating to the content of this article will be borne by them.

\section{Open Access}

This is an Open Access article that uses a funding model which does not charge readers or their institutions for access and distributed under the terms of the Creative Commons Attribution License (http://creativecommons.org/licenses/by/ 4.0) and the Budapest Open Access Initiative (http://www.budapestopenaccessinitiative.org/rea d), which permit unrestricted use, distribution, and reproduction in any medium, provided the original work is properly credited.

\section{REFERENCES}

1. Guangxi Zhuang; Guangxi Chinese herbal medicine standard. Nanning: Guangxi Science and Technology Press; 1992; pp 31-32.

2. Jian J, Liu $X$, Huang RB. The protective effect of two flavone monomers of Yulangsan on myocardial hypoxia/reoxygenation injury in rats. Chine Pharma Bull 2009; 25(7): 942-945.

3. Guo YJ, Wen K, Zhang SJ. The effect of Yulangsan saponin on the CCl4-induced hepatic fibrosis in rats. Chin Pharma Bull 2012; 28(4): 554-558.

4. Shwe $H$, Huang RB, He QL. The protective effects of Yulangsan polysaccharide on anti-tuberculosis drugs induced liver injury. West Chin J Pharma Sci 2015; 30(3): 292-294.
5. LV JH, He M, Huang JC. The effect of Yulangsan flavonoids on myocardial ATP enzymes and apoptosis proteins of myocardial ischemia reperfusion injury. Chin J Exp Tradit Med Formu 2010; 16(13): 162-166.

6. Zeng R, Huang JC, Chen CX. The study of antiinflammatory effect of Yulangsan extraction. Nat Prod Res and Dev 2014; 26: 1889-1892.

7. Huang $R B$, Duan $X Q$, Jiao $Y$. The study of the protective effect of Yulangsan extraction on mice acute chemical liver injury and its mechanism. J Guangxi Med Univ 2003; 20(6): 874-877.

8. Nong $Z H$, Tao $L Q$, Zuo QY. The protective effect of Yulangsan water extract on duck chronic hepatitis $B$. Chin J Exp Tradit Med Formu 2015; 21(10): 158-161.

9. NIH. Principles of Laboratory Animal Care. NIH publication revised 1985; 85-23, NIH: Maryland, USA.

10. $X u$ SY, Bian $R L$ and Chen $X$. Pharmacological experimental methodology. People's Medical Publishing House; 2003; pp 1346-1348

11. Chen HG, Nian GX, Yang XB. The protective effect of total phenolics acid of oenanthejavanica on $D$ galactosamine hydrochloride-induced liver injury. Pharma J Chin People's Liberation Army 2009; 25(60): 492-495.

12. Yang YL; Clinical Laboratory Diagnosis of liver disease. China Traditional Medicine Press; 2007. 65.

13. Bradford M. M. A rapid and sensitive method for the quantitation of microgram quantities of protein utilizing the principle of protein-dye binding. Anal Biochem 1976; 72(1-2):248-254.

14. Wang CZ, Zheng GY, Chen WY. Protection of Yinkechun soft capsules on acute liver injury induced by carbon tetrachloride and D-galactosamine. Pharmacol Clin Chin Mater Med 2007; 23(1): 31-32.

15. Pirinccioglu AG, Gokalp D, Pirinccioglu $M$. Malondialdehyde (MDA) and protein carbonyl (PCO) levels as biomarkers of oxidative stress in subjects with familial hypercholesterolemia. Clin Biochem 2010; 43 (15): 1220-1224.

16. Mottaran E, Stewart $S F$, Rolla R. Lipid peroxidation contributes to immune reaction associated with alcoholic liver disease. Free Radic Biol Med 2002; 32(1): 38-45.

17. Cigremis $Y$, Turel $H$, Adiguzel $K$. The effects of acute acetaminophen toxicity on hepatic mRNA expression of $S O D, C A T, G S H-P x$, and levels of peroxynitrite, nitric oxide, reduced glutathione, and malondialdehyde in rabbit. Mol Cell Biochem 2009; 391(1): 257-257. 